\title{
Plotinus on the Soul's Omnipresence in Body
}

\author{
Gary M. Gurtler, S.J. \\ Boston College \\ gurtlerg@bc.edu
}

\begin{abstract}
In examining Ennead VI 4[22], we find Plotinus in conflict with modern, i.e., Cartesian or Kantian, assumptions about the relation of soul and body and the identification of the self with the subject. Curiously, his images and exposition are more in tune with Twentieth Century notions such as wave and field. With these as keys, we are in a position to unlock the subtlety of Plotinus' analysis of the way soul and body are present together, with sensation structured through the body and judgment coming from the soul. The problem of the self concerns not only the unity of the self in terms of body and soul, but also how the self is constituted in relation to other selves, both keeping its individuality and sharing its experiences at the same time.
\end{abstract}

\section{Keywords}

self, subject, sensation, judgment, consciousness, experience, participation, immanence, transcendence, language

\section{Introduction}

Plotinus' discussion of the relation of soul to body is a particular instance of his doctrine of participation, where higher is related to lower, intelligible to sensible, and form to matter. ${ }^{1}$ I have selected three chapters from

1) A little over fifty years ago Norris Clarke, S.J., published "The Limitation of Act by Potency: Aristotelianism or Neoplatonism," The New Scholasticism, 26 (1952) 167-194, which highlighted the role of Plotinus in formulating some of the fundamental distinctions operative in medieval philosophy. He singled out the doctrine of participation and the idea of infinity and showed how they went beyond the limits of classical Greek thought. At the same time his work challenged some of the basic historical assumptions of Thomists about 
Ennead VI 4[22] for consideration. The first, VI 4[22] 6, deals with the problem of other selves and specifies the roles of body and soul in accounting for experience. VI 4[22] 7 maintains that the soul is present to the body as undivided and Plotinus uses carefully chosen images in an attempt to articulate the soul's omnipresence. Finally, VI 4[22] 8 distinguishes the spatial and quantitative categories applied to corporeal objects from the immaterial modes of the soul's presence to body. Plotinus must clarify the meaning of immateriality and transcendence, distinguish omnipresence from immanence, and reflect on the peculiar way language derives from sense experience and yet mirrors the intelligible as an activity. All of these concerns distance him from Cartesian dualism and Kantian accounts of experience, but resonate with certain developments in contemporary thought that break from the objective stance dominant in classical modern thought. ${ }^{2}$

\section{The Problem of Other Selves: VI 4[22] 6}

In VI 4[22] 6,1-21, Plotinus raises four questions about soul and body that immediately alert us to a context much different from that of the modern subject and its relation to an external world.

the relation of scholastic philosophy, and especially St. Thomas, to Plato and Aristotle. I have appreciated more and more the unusual openness and self critical character of Clarke's historical method, and have attempted to extend his reflection on participation to the relation of soul and body in this paper.

2) My article, "Plotinus and the Platonic Parmenides," International Philosophical Quarterly, 32 (1992) 443-57, examines Ennead VI 4[22] 3 and 9. VI 4[22] 3 distinguishes immanent forms, related to Aristotelian sensible qualities, and omnipresent forms, such as souls and intellect itself related in different ways to sensible substances. Atsushi Sumi, "The Omnipresence of Being, the Intellect-Intelligible Identity and the Undescended Part of the Soul, Neoplatonism and Indian Philosophy (Albany, SUNY Press, 2002) alerted me to the difference between immanence and omnipresence, especially clear in VI 4[22] 3. VI 4[22] 9 distinguishes between substance and number, articulating the difference between corporeal nature and the immaterial in terms of whether or not division can be applied to them. The present article applies these distinctions in the specific case of soul and the complicated ways it can relate to body. Eric Perl, "The Togetherness of Being and Thought," Proceedings of the Boston Area Colloquium in Ancient Philosophy (Brill, 2007), is in substantial agreement with this theme, and makes explicit comparisons with the phenomenology of Husserl. Perl's earlier paper, "The Living Image: Form and the Erotic Intellect in Plato," American Catholic Philosophical Quarterly, 69 (1995, ACPA Proceedings Supplement) 191-204, also features engagement with the nihilism rooted in Nietszche's attack on Platonic forms. 
He asks: (1) Why does the soul in one body not come to another $(6,1)$ ? (2) Is the soul in one body actually the same as in another (6,3-4)? (3) Why is the same soul in the foot and hand of one body, but not the same in different parts of the sensible all (6,5-6)? (4) And why is one soul not con-

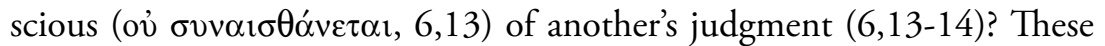
questions make explicit the consequences that come from Plotinus' earlier distinction, in VI 4[22] 1-3, between qualitative forms as divisible in body and souls as powers that are not divisible, but present to the body everywhere as a whole. In addition, souls are all akin and the same in kind, so Plotinus has to show why a soul is present in one body rather than another. Finally, since all souls are unified at the level of intellect, Plotinus needs to explain how they can have distinctive or individual experience at the sensible level. We see immediately that these problems are different from those of classical modern thought. They assume a relation between soul and body that rests on the divisibility of body rather than the idea of extension and on the nature of the soul as an active power and not as a thinking thing. ${ }^{3}$ Plotinus' puzzle, thus, is to explain how experience can be individualized in relation to the embodied soul, and why embodied souls are not aware both of their higher selves and their common unity. In responding to these questions, Plotinus delimits the roles of body and soul in human experience in such a way as to ground both the specificity of each individual's experience and the power of the soul that always makes it possible to share this experience with another.

His discussion of the first three questions provides reminders of positions developed elsewhere in VI 4[22] or in other early treatises. Thus, for question (1), it is not the soul that goes in search of a body, but rather the body is the seeker (as in 3,17). This position preserves the independence of being as a higher reality and the non reciprocal relation between this intelligible being and sensible becoming. For the next two questions, Plotinus indicates an element of tension in his theory of ensoulment. On the one hand, no two bodies share the same soul (question 2), even though they

\footnotetext{
3) See "Plotinus and the Alienation of the Soul," The Perennial Tradition of Neoplatonism (Leuven University Press, 1997), pp. 221-234 for a fuller discussion of Cartesian assumptions about extension and the contrasting Plotinian assumptions. That article argues against John Dillon, "Plotinus, the First Cartesian?" Hermathena, 149 (1990) 19-31, and Eyjolfur Emilsson, "Plotinus and Soul-body Dualism," Companions to Ancient Thought 2: Psychology, ed. Stephen Everson (Cambridge University Press), 148-65.
} 
are all parts of the one body of the universe, and, on the other hand, all the parts of a single body do share the same soul (question 3). Theoretically, the two positions are not radically dissimilar, and Plotinus' brief comments here depend on his analysis in VI 4[22] 3 of souls as active powers going out from intellect. Souls vary in power and thus relate to the sensible cosmos to varying degrees. Conversely, certain bodies attract different souls. These distinctions are not part of the Cartesian or Kantian notion of soul or mind, and thus may seem bizarre or irrational, the product of Plotinus' mystical imagination. It is therefore helpful to find an analogue, so to speak, in contemporary wave theory, giving a context to understand what Plotinus might mean and thus making his position surprisingly plausible. If we compare souls as active powers to radio waves or fields, and bodies to radio receivers, we have an image that is both simple and clear. This comparison combines things that are everywhere the same, the waves, but can be received by different things and in varying degrees, depending on the tuning and the quality of the radio. It is an image very much at home with Plotinus' Neo-Platonism, as we shall see in examining VI 4[22] 7, and yet is immediately accessible to us.

Assuming its plausibility, we can attempt to tie Plotinus' comments into the larger discussions to which they allude. The restriction that only one soul comes to be possessed by a body derives in part from the nature of bodies as divided and thus as blocking out another body from sharing the same soul, and in part from the nature of souls as already different at the intelligible level. ${ }^{4}$ Each body is thus qualified in such a way that it is apt to receive only one particular soul. This principle is, of course, borrowed from Aristotle, but Plotinus is not always comfortable with it, as his arguments against the soul as entelechy amply prove. ${ }^{5}$ Finally, that foot and hand

4) In VI 9[9] 8,29-36, Plotinus makes a contrast between the separation and cutting off of bodies by place and the otherness that makes bodiless things both plural and transparent to one another, especially at the intelligible level. In the present context, Plotinus is articulating what happens when the separation due to bodies is in tension with the openness of one soul to another.

5) Jesús Igal, "Aristóteles y la evolución de la antropología de Plotino," Pensamiento, 35 (1979) 315-346, discusses Plotinus' use of Aristotle's "qualified body" for the first time in the present context and later in III 6[26] 1,3 (p. 329) and yet his rejection of the soul as entelechy in IV 7[2] $8^{5}$, which Aristotle clearly associates with the qualified body, as Igal notes (p. 331). 
share the same soul is the easier position for Plotinus to defend, since it is the very purpose of soul in going out from the intelligible to bring unity to the sensible and to be present to it as a whole.

With these initial clarifications, we turn to question (4) and consider the consequence Plotinus draws from the fact that two separate souls are present in two bodies, and differ by their additions or circumstances ( $\tau \alpha i \bar{\varsigma}$ $\pi \rho 0 \sigma \theta \dot{n} \kappa \alpha 15$, VI 4[22] 6,5), as he puts it. Plotinus argues that if the sensations ( $\alpha i \sigma \theta \eta \dot{\sigma} \sigma 1 \varsigma)$ are different, it must be said that the experiences $(\pi \dot{\alpha} \theta \eta$, $6,7)$ occurring with them are also different. These are the different circumstances judged by each individual, based on the distinction between the soul's power of judging and the content judged.

Various then are the things judged, not the judging; moreover, the same judging expert is engaged in one experience after another, and yet the self is not acted upon, but the nature of such a body. It is as if our selfjudges both the pleasure in the toe

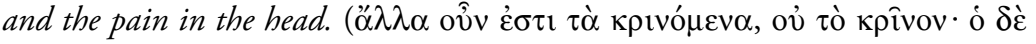

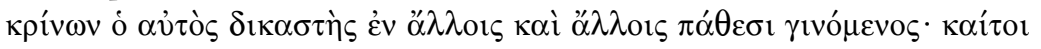

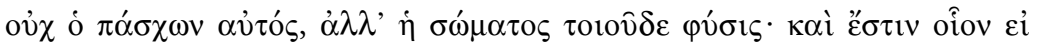

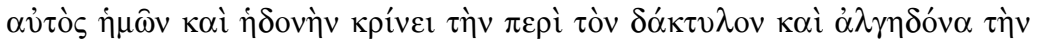

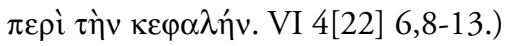

Judging remains a power residing in the soul, while sensations and experiences are ways in which a certain kind of body is acted upon. Judging is the same power in all souls, yet particular judgments are not acts of the soul alone, but depend on the additions arising from corporeal experiences. Plotinus is making a careful demarcation between the roles of body and soul in order to establish both the differences in experience between one individual and another and how such experiences can nonetheless be shared through the judgments made about them.

He continues with the puzzle that question (4) raises, why we are not conscious of one another's judgments. Here the different levels of the self come into play. The higher self is always unified with others in full knowledge of the intelligible, but the lower self unifies a particular body by its presence and, thus, its judgments are specified in relation to that body. ${ }^{6}$

\footnotetext{
6) In I 2-3 [19-20], the treatises "On Virtue" and "On Dialectic," Plotinus first discusses the two selves. In I 2[19], the discussion begins with the relation of virtues here below and what corresponds to them at the intelligible level. Plotinus articulates quite clearly the
} 
Why then is one [soul] not conscious of the judgment of another? Precisely because it is an act of judgment, but not an experience. Further the soul itself having judged does not say "I have judged," but it only judged, since even sight in us does not say to hearing ["I have judged"], although both judged, but reasoning is over both, but is different from both. Moreover, reasoning often saw the judgment in the other and had an understanding of the other's experience. ( $\delta i \dot{\alpha} \tau$ '

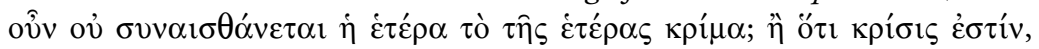

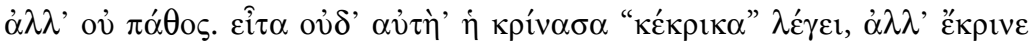

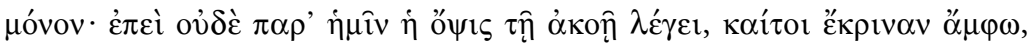

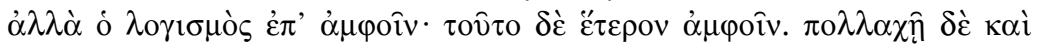

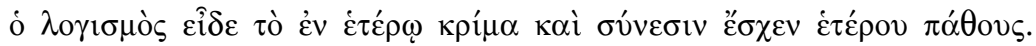
VI 4[22] 6,13-19.)

The consciousness under dispute implies in the case of empirical judgments something close to the literal meaning of the etymological roots, that one individual would actually co-sense the judgment of another. Plotinus, in what at first may seem an odd move, states that such co-sensing does not occur because a judgment is involved rather than a sensory experience. Such a judgment, he argues, is neither sufficiently external to be sensed directly by another nor sufficiently internal to be shared automatically on the intelligible level.

Judging is, to be sure, an act of soul, and thus not something the body undergoes nor something that affects the body as do the sensations and experiences that are judged. It is, however, not an act of the soul alone about what is akin to it, ${ }^{7}$ but an act of soul about the experiences of the body. This act of the soul is not self-reflective, any more than vision or hearing are (none say "I have judged"). Self-reflection is identified rather with reasoning, or perhaps more precisely with the one who reasons, the lower self in this instance. It is in reasoning that empirical consciousness is

difference between reciprocal relations at the same level and the non-reciprocal relation between different levels, also operative in VI 4[22]. In I 2[19] 5-6, this distinction is applied to the two selves, the real self at home in intellect and the other self lost in the sensible world. I 3[20] continues this distinction in terms of the knowledge acquired for the ascent of the soul to the intelligible.

7) Plotinus indicates in I 6[1] 6,17-18 that intellect and the things of intellect are the soul's own, and not alien to it as are its experiences in relation to the body. As the soul is more completely identified with what is its own, it is at the same time able to bring more order and beauty into the sensible world, which is the reason for its descent. 
centered, and this consciousness is open to the consciousness of another in the same way it is open to self-consciousness, through reasoning. It can see another's judgment and can understand another's experience by reasoning from words or actions to the judgment or experience that motivates them, exactly as it knows itself on the empirical level.

\section{One Over Many: VI 4[22] 7}

In VI 4[22] 7, Plotinus examines the presence of the same over all ( $\dot{\varepsilon} \pi \grave{i}$ $\pi \alpha ́ v \tau \alpha, 7,1)$, returning to issues mentioned already at VI 4[22] 3,2 and 3,6, where powers go out from intellect to one living being after another. In the present context he expresses it as how each of the many sensible objects, situated in diverse places, is not without a share of the same. There is an element of ambiguity in these statements. The problem in the earlier context is the presence of the same intelligible form in numerically distinct bodies. While this continues to be assumed here, Plotinus also adds the soul's numerically singular presence in the many parts of one body and its capacity to unify a diversity of sense impressions from the multiplicity of sensible objects. Both aspects of the problem, however, deal with a common underlying issue, the presence of soul everywhere as a whole. He continues with conclusions that have already been established. (1) The same is not divided up in the many, but the divided many are brought back up to that unity (cf., VI 4[22] 3,15-17), and (2) our opinion that the same has been taken apart, he suggests, comes from the scattered character of these many (cf., VI 4[22] 4,1-5), as if one were to divide that which lays

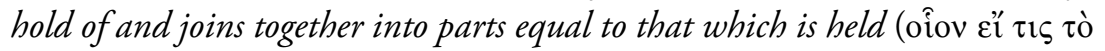

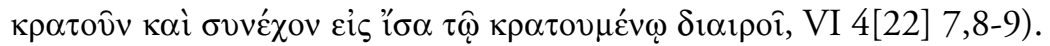

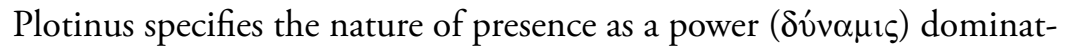
ing and unifying an object without losing its own unity. The images he uses to elucidate this power are decidedly physical: bodily strength in a

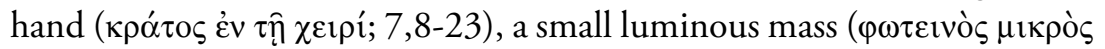

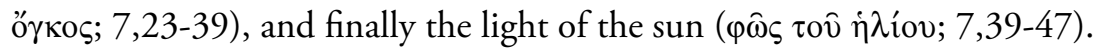
In each case, the image illustrates the presence everywhere of an undivided power, but then each one is corrected to remove the physical aspect of the image so the immaterial nature of the soul's presence to the body can shine forth. These images are thus designed to add persuasive force to earlier arguments that the soul's presence to the body is not as a quality that is 
essentially divisible in quantity, but rather as an activity that is present as a whole throughout the body.

The first image $(7,8-23)$ is of a hand grasping an entire body, a long plank, and something else $(7,10)$. The text does not specify, so the grasp may be upon all the objects taken together or each one considered separately. By way of filling out his examples, let's assume that the body is a ball. A hand grasping a ball surrounds it more completely than one grasping a plank, which tends toward the midpoint for balance. The strength in the hand has varied effects: the ball can be thrown and the plank carried. Alternatively, someone might be attempting to hold all the objects at once. Plotinus claims that the grasp in the hand is not divided up into parts equal to those of the objects grasped, but the difficulty is determining what he means. In comparing the grasp of ball and plank, there is a contrast between a grasp that surrounds an object more or less completely and one that holds on to no more than a small portion of its total length. In neither case, however, is it necessary or possible to have parts of the hand touching all the parts into which an object can be divided.

What happens is that through this contact of hand and object, the strength in the hand becomes a force or control permeating the object. This control extends in undivided fashion throughout the entire ball or plank: when the ball is thrown, the force propels it completely, and when the plank is carried, the force extends to the untouched parts of its length and not only the small portion firmly in one's grip. The relationship of the hand's strength to this control or force in the object is non reciprocal, but not entirely.

As far as the hand touches, so its power, it seems, is bounded, but yet the hand is

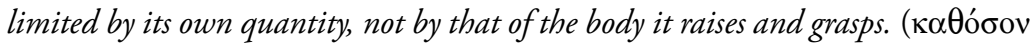

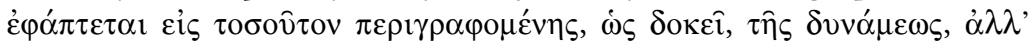

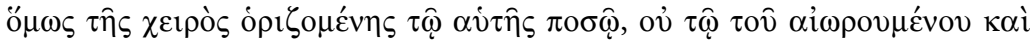

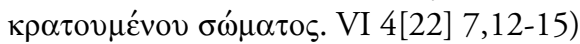

This illustrates well how a higher power (strength in the hand) is present in something lower (its control over or force in the object), but also that the bodily character of this relationship needs qualification, since the hand is itself physical, and thus both quantitatively limited and external to the object. The first part of the statement indicates that the control from the hand extends throughout the object, which serves as the boundary of its 
operation, in the same way that souls were described in VI 4[22] 6 as dwelling one to a body. The force is "received" by the object and does not go beyond it. The force is clearly present in the object lifted, but remains centered in and dependent on the strength of the hand, which is external to the object in a way that the soul is not external to the body. The object does not become alive or possess this force on its own, no matter how much strength the hand exerts. The real limit on what the hand can do, moreover, comes from the quantity of the hand itself, how much strength it has. It is at this point that hand and soul part company in their relation to body. The quantitative nature of the hand needs to be corrected when applied to the soul's presence: take away the bodily mass, but leave the power $(\delta$ v́v $\alpha \mu v)$ intact. This power permeates the whole object with all its parts.

The soul is unlike the hand, which is a quantity itself and external to the object, since the soul and its power are present in a body in the same pervasive way the force is present in an object, with the body acting as the boundary of its operation. The immateriality of the soul allows it to be present much more intimately, manifest in making the body alive with its own power. Nevertheless, the separation between hand and object also plays an important role, indicating not a physical separation, but soul's radical independence from the body. One can accurately say that the soul is present to matter in Plotinus' scheme in such a way that matter hardly seems changed at all, however much the presence of soul enlivens it, and that soul never really belongs to body, however much it functions through it.

The second image continues this reflection $(7,23-39)$ by imagining a small luminous mass within a large, transparent sphere, so that the light from this small center fills the whole sphere, whose shell is opaque in such a way that no light from outside the sphere can shine within it. Thus, the transparent space inside the sphere is wholly filled by the light that comes from this luminous center. His tendency to think of light as quasiincorporeal emphasizes the distinction made in the previous image between the force or control in the object and the strength in the hand. Here, however, it is the luminous mass that comes off the poorer, since the light that fills the sphere is the point of the image. If that mass is removed, light permeates the sphere perfectly, so that no point of origin can be imagined, but just the presence of light everywhere. This flips the point of view of the previous image around. We are no longer on the outside, looking at a power going out of the hand to some object, but Plotinus, as it were, has 
moved us inside the object itself. The soul is present in us much as light is present in the sphere, without a point of origin that can be identified and with the same result of amazement about a power present everywhere in this way. Wherever we look, light and soul are equally present.

The last image applies the previous one to the case of the sun shining and lighting up the air around us (7,39-47). This application presents a crucial point of contact with the major text lurking behind this whole treatise, Parmenides 131b3-4, where Parmenides confuses the young Socrates about the nature of the forms by using the image of day and sail to illustrate how a form is present to multiple bodies. Plotinus, in correcting the image, substitutes the sun, as the one source of light, for the day used by Parmenides. The light, as the effect produced by the sun, lights the air everywhere but is not itself divided. Where objects block it or cut it off, they do so only on the side away from the sun, indicating that the light permeates the air thoroughly, as the effect of one cause. He comments further that the image is still in need of refinement to fit the relation of souls or ideas to bodies. Here too the analogy is shown to limp precisely because the sun, as the origin of light, must be located at some definite place. If this introduction of the spatial is eliminated, then the parallel would be exact: a pure power that could not be localized, but is present everywhere as one and the same. ${ }^{8}$

\section{Language about the Immaterial and the Division of the Corporeal: VI 4[22] 8}

Plotinus continues in VI 4[22] 8 to explore the nature of the immaterial as different from light. He argues that light comes from a body and that body necessarily involves place. The immaterial, however, does not need body, since it is prior to body, and is set firm in itself or, even more strictly, does not need to be set firm at all. Plotinus is revisiting two earlier passages. In the first, VI 4[22] 2,18, the sensible cosmos is set firm in the intelligible, and in the second, 3,4, the intelligible is set firm in itself, with souls like rays

\footnotetext{
8) My article, "Plotinus: Matter and Otherness, 'On Matter' (II 4[12])," Epoche, 9 (2005) 197-214, explores the careful analysis Plotinus gives to Aristotle's prime matter in relation to the corporeal. His distinction about the relation of the corporeal to various forms is the background for his work here on the relation of body to soul.
} 
of light shining out from it. The second context is very much like the present discussion in VI 4[22] 7-8, where light also radiates from a source. In one sense, then, the immaterial is set firm in itself, like the intelligible in VI 4[22] 3,4, but, in another sense, since being set firm is more accurately said of the relation of the sensible to the intelligible, as in VI 4[22] 2,18, its use for the immaterial or the intelligible is not completely appropriate.

The present discussion thus refines the earlier remarks, since it is designed to differentiate more exactly the nature of the corporeal and that of the immaterial, and to redress the confusion that comes from using terms derived from sensible experience to describe the immaterial. Plotinus presses the argument by excluding place from the immaterial.

Since the [immaterial] thus has the kind of nature that does not have a point of origin from where it could start either as being from some place or from some body,

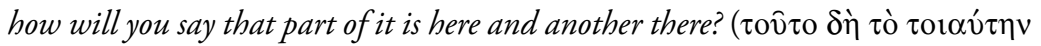

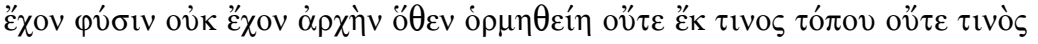

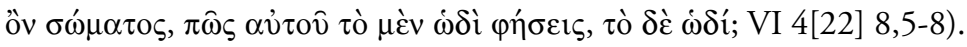

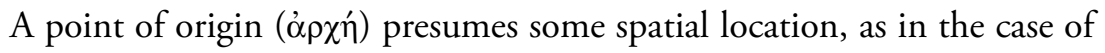
light flowing from a luminous mass into the surrounding air. The immaterial, however, does not have spatial location and thus cannot relate to objects in the external way that light proceeds from its source, or even force from a hand.

A number of conclusions follow from this: since it cannot be localized, the immaterial cannot belong to a body, and thus cannot be divided up in the parts of a body. Plotinus introduces participation, Plato's term for the relation of a form or idea to its instances, as the alternative to the way a luminous source or a hand's strength relate to objects. Participation seeks to retrieve the side of these images that is like the immaterial and thus

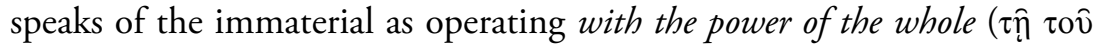
ö $\lambda$ ov $\delta v v \alpha ́ \mu \varepsilon 1,8,10)$. The participant, like the plank or surrounding air of VI 4[22] 7, possesses this whole insofar as it can, while the immaterial whole remains unaffected, neither becoming this other nor being divided in it. As in VI 4[22] 1, there is a contrast between how a quality relates to a body and how, in the present case, the immaterial relates to a body. A

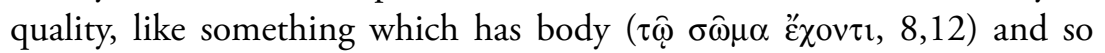
subject to affection and division as having parts, is like an affection or form ( $\pi \dot{\alpha} \theta_{0} \varsigma \hat{\eta}$ દî̉os, 8,14-15). As an affection, it can change and, as form, it is 
numerically divisible in the parts of the body. In other words, the quality of an object, its whiteness, can be influenced by another quality, such as size. It is thus divisible, changing in some parts but not in others.

The immaterial, on the contrary, as that which belongs to no body ( $\mu \eta \delta \varepsilon v o ̀ \varsigma \sigma \omega ́ \mu \alpha \tau o \zeta, 8,15)$, but body wishes to belong to it, repeating a phrase from 3,15, is impervious to bodily affections and cannot be divided. The immaterial relates to a body in a more primary sense and as a whole. The paradox here is due to the limitations of language, but can be easily illustrated by considering the image of the plank. The control of the hand affects the plank as a whole, but neither as a quality itself nor as dependent on any quality, whether the color, shape or size of the plank. The body can be painted different colors or given a different shape, but the control is present so long as it remains numerically one. Affection refers both to the qualities a body can have and to something like the control affecting the body as such and as a whole. In this latter case it refers to the Platonic transcendent form in which bodies participate as a whole, while in the former case it refers to Aristotelian immanent forms, qualities received in bodies in relation to size as divisible. ${ }^{9}$ Plotinus denotes this difference by identifying substance with intelligible forms and accidents with sensible qualities.

Body and not body are thus differentiated as being divisible or indivisible, which Plotinus seeks to clarify through the idea of size. What has size can participate in what does not have size, but it does so without in any way dividing the sizeless. Thus, participation is a non reciprocal relationship. Division and size, on the contrary, are mutually reciprocal, so that, if the immaterial were to be divided by what participates in it, it would automatically have to have size. How then is this immaterial one present in the many things that are divided from one another? The affection is in the many, Plotinus says, and the many are being fitted to the one when it is seen in them.

Perhaps shifting images might clarify what this means. In recording a concert, only one event is the cause, the concert itself, but an indefinite number of recordings can be produced. All of them are of the same event,

9) My article, "Matter and Otherness," pp. 203-06, discusses II 4[12] 9-10, 12, about the relation of size and other such qualities, as immanent forms, in relation to the corporeal; see also "Platonic Parmenides," pp. 445-48. 
even if they vary in quality, with any difference due to defect or limitation in the medium of the recording and not at all to the concert itself (which may indeed have defects in performance, equally present in all recordings). The event, moreover, is reducible neither to a recording nor to the totality of recordings, but is something in itself. The difference for Plotinus is that while a concert is an event that also shares in the transitory character of the sensible, like the strength in the hand, the immaterial has a similar independence as cause, but none of the limits of an event in the sensible world, so that it is just itself and never departs from itself. This is true whether one is considering discrete objects or the sensible cosmos as a whole. The immaterial does not grow or diminish in size to deal with the whole cosmos or only one atom within it: it has no size and the quantitative in no way applies to it.

Plotinus mentions some attributes at this point that are connected with the material and which therefore do not apply to the immaterial: so much (

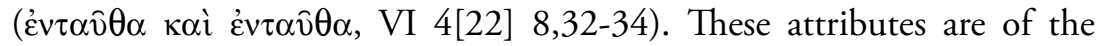
bodily as divisible and as in place. Division includes both the idea of size, since a body is potentially divisible into units, and of quality, since a body can have qualities of different kinds in its various parts. For place, moreover, the idea of somewhere includes the idea of here and there, since "where something is" presupposes "where it is not." Division, thus, tends to express for Plotinus not only the quantitative but the qualitative character of a body. Division, further, seems reducible to place, since it situates one body or its parts in relation to others, the necessary condition for the presence of quantity and quality. Both ideas involve affection or change, bringing in the idea of time.

The immaterial, on the contrary, is first defined as having no "here," as not in place and thus as indivisible, since the fundamental distinction of part from part is impossible, thus eliminating the possibility of quantity and quality alike. Since the immaterial does not have part distinct from part, the many desire ( $\tau \dot{\alpha} \pi \circ \lambda \lambda \grave{\alpha} \dot{\varepsilon} \varphi \dot{\varepsilon} \varepsilon \tau \alpha 1,8,38)$ to participate in it and

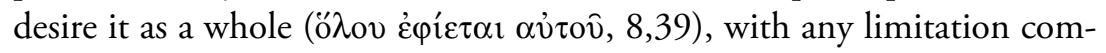
ing from their side as recipients, repeating the point made at 3,17 , where being is desired. Plotinus further clarifies the non reciprocal nature of participation, since the many participate in the immaterial as a whole insofar as they can, but as if not participating in it, a point made previously at 
VI 4[22] 3,30ff. They participate in it insofar as they are like it, but they do not participate in it insofar as it does not belong to them.

Using our example, the recordings are like the concert, but at the same time they are not the concert at all. Only in this way does Plotinus consider it possible for the immaterial to remain whole both in itself and in the objects that participate in it. He ends by saying that if it is not whole, it is not itself, nor on the contrary will participation be of what the many desire

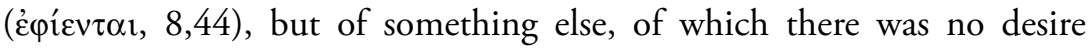

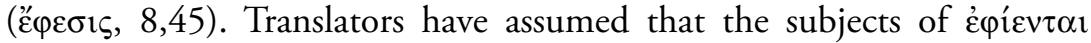
are souls or men rather than the many of 8,41 , but it is not clear that needs to be the case. The term, desire, has been used throughout this treatise (as opposed to I 6[1] 7,3 and V 9[9] 8,29, which certainly do restrict it to souls) of the necessary relation of any lower to its higher. If the whole is not so and thus not itself, it is already many, and could not be the object of desire for the sensible many, since what they need, singly or together, is the unity that comes from the whole. The argument in VI 4[22] 9 continues the discussion of parts and wholes in general, making the intrusion of souls in this one phrase at the conclusion of VI 4[22] 8 less likely.

\section{Conclusion}

Plotinus understands the soul's complexity both vertically and horizontally. The problem horizontally is to account for the individual experience of the lower self, what constitutes one's consciousness, and at the same time for the possibility of sharing that experience with others through discourse or language. The problem vertically is to show that the lower self is ultimately a manifestation of the higher self, which dwells within the intelligible world and is unified in being and knowing with all intelligible beings. I suppose that this may seem outlandishly fantastic for those who identify the self with the subject of modern philosophy, but Plotinus is doing no more than articulating what Plato describes in the Allegory of the Cave. That is, human beings share in the making of a world through imitation, by means of language most primordially, and yet are somehow not limited to this imitation but can see it as if from the outside. This paradoxical situation captures our horizontal link to others, especially through language, and also the vertical link to the transcendent, that allows us to recognize our predicament without escaping it. Plotinus assumes this 
general problem of a shared experience, but explores in more detail how we are capable of individual experience that is not known to others unless we share it in some way. This sharing need not be intentional, since others can infer, as they often must, what is going on within us from our actions as well as our words.

The next part of my paper explores a series of images that Plotinus uses to articulate how the lower is related to the higher. As always, he uses analogies that derive from our experience, such as a hand grasping an object, a luminous mass lighting up a sphere, and the sun's light shining in our world. What is distinctive is that all these images are of activities, because activities are for Plotinus most like immaterial, intelligible causes. I used both the analogy of recording a concert and our familiarity with waves and fields in the transmission of radio or television to illustrate what Plotinus has in mind. The receiver always receives according to its capacity, say as color or black and white, or as stereo or monophonic. What is broadcast is whole in the entire receptive field, so that my radio does not pick up part of a broadcast and yours another; we both receive the whole, even if my home entertainment system is more advanced than yours.

Plotinus' point about the independence of the source and the way the participants seek out the source and receive it as a whole are well illustrated by these examples. Nonetheless, his corrective is still needed, since, like language, these analogies derive from sensible experience and thus are in constant need of correction to bring out the nature of the immaterial. Aristotle's categories for the accidents, especially quantity and its consequent divisions, are the constant targets of the corrective needed for understanding the immaterial. Plotinus does, however, combine Aristotle's act and potency with Plato's participation to establish not only the nature of the immaterial but how the intelligible and the soul as transcendent are present as a whole to the whole sensible cosmos and particular bodies within it. 